Página inicial: 291 - Página final: 305

TIPO DE ARTÍCULO: de Reflexión

\title{
LA INFLUENCIA DE LA TEOLOGÍA DE LA LIBERACIÓN EN EL PENSAMIENTO PEDAGÓGICO DE PAULO FREIRE Y DE LUIS OSCAR LONDOÑO ZAPATA. ${ }^{6}$
}

THE INFLUENCE OF THE THEOLOGY OF LIBERATION IN THE PEDAGOGICAL THINKING OF PAULO FREIRE AND DE LUIS OSCAR LONDONO ZAPATA.

Recibido: Junio 2014 Revisado: Septiembre 2014 Aceptado: Octubre 30 de 2014

Por: Sandra Arcila N ${ }^{1}$, Marcel Gómez F⿻ ${ }^{2}$, Karina Gómez G ${ }^{3}$, Ricardo Gómez G4, Maribell Urrego M. ${ }^{5}$

\section{RESUMEN:}

El presente documento resultado de investigación, hace un recorrido por el pensamiento pedagógico de Paulo Freire y Luís Oscar Londoño Zapata, su relación con el pensamiento cristiano personalista, la influencia de la Teología de la liberación y cómo a través del conocimiento de la propia realidad, el sujeto puede autodeterminarse.

\section{PALABRAS CLAVE:}

Teologia, liberación, popular, educación, pedagogía critica, autonomía, reflexión.

\section{ABSTRACT:}

This current document, which is the result of a piece of research, makes a tour of the pedagogic thinking of Paulo Freire and Luis Oscar Londoño Zapata, its relationship with the personalist Christian thought, the influence of the theology of liberation and how through the knowledge of reality itself, the subject can determine himself.

\section{KEY WORDS:}

Theology, Liberation, Popular, Education, Critical Pedagogy, Autonomy, and Reflection.

\footnotetext{
${ }^{1}$ Licenciada en básica primaria, universidad Pontificia Javeriana, Docente secundaria, gobernación de Antioquia. Colombia. Contacto: maestriaedurural5@gmail.com

${ }^{2}$ Licenciado en matemáticas, universidad católica de oriente. Docente secundaria, Gobernación de Antioquia. Colombia. Contacto: maestriaedurura15@gmail.com

${ }^{3}$ Licenciada en matemáticas, universidad católica de oriente. Docente secundaria, Gobernación de Antioquia. Colombia. Contacto: maestriaedurura15@gmail.com

${ }^{4}$ Licenciado en Teología, universidad San Buenaventura Bogotá. Docente Universidad Católica de Oriente. Colombia. Contacto: maestriaedurura15@gmail.com

${ }^{5}$ Licenciada en educación preescolar, tecnológico de Antioquia. Docente preescolar, Gobernación de Antioquia. Colombia. Contacto: maestriaedurura15@gmail.com
} 


\section{Introducción.}

Paulo Freire se consideraba un hombre creyente y católico, esta es una realidad que no se puede deslindar de su pensamiento y praxis pedagógica. Su identidad de cristiano, la refleja en sus escritos y en su forma de vida, pues se nota una preocupación por la persona humana, por su autonomia, por su libertad, sin perder de vista el valor trascendente del hombre. Se podria decir, que Paulo Freire se ubica en una filosofia personalista la cual enfoca al ser humano como persona capaz de amar, especialmente a través de su corporeidad, de sus capacidades intelectuales y desde su misma afectividad. El pensamiento de Freire guarda una profunda relación con el pensamiento cristiano, humanista y personalista; para él no existe el hombre fuera de la sociedad y mucho menos sin educación, pero tampoco existe la sociedad sin educación y por lo tanto, en palabras de Freire "El hombre es un ser de relaciones y no solo de contactos, no solo está en el mundo sino con el mundo" (Hernández, 2010. p 28).

Según Hernández (2010) el hombre se encuentra llamado a dejar su animalidad para vivir en la sociedad y avanzar en la autoconciencia que lo lleve a la posibilidad de ser un ser más humano. Solo en la educación, el hombre puede hacerse consciente de su realidad y ser capaz de reconocer al otro, ser capaz de reconocer el rostro del otro, en medio del sufrimiento humano, esta es una manera existencialista de entender la educación y de entender a quien se educa, al hombre, para ser un mejor ser humano.

Tanto quien se educa, como quien es educado, se enfrentan juntos al acto de conocer; pero la misión del educador sobre quién es educado, consiste en despertar el espíritu crítico del educando para guiarlo a la tarea de su realización personal, a la tarea de ser hombre más autónomo, libre en sus decisiones, creativo, comprensivo, pero sobre todo, que genere conciencia de sí mismo y de los demás. Esto no quiere decir que el educando sea solo un objeto de la acción educadora del maestro, sino que el educando debe educarse a sí mismo, generando conciencia de lo que ha perdido y de su capacidad creadora; al respecto, Freire afirma "La tragedia del hombre moderno es que hoy, dominado por la fuerza de los mitos y dirigido por la publicidad organizada, ideológica o no, renuncia cada vez más, a la capacidad de decidir. Está siendo expulsado de la órbita de las decisiones" (Freire, 1970, p. 33).

Para Hernández (2010) al hombre perder su capacidad de tomar decisiones, es cosificado y deja de ser sujeto, convirtiéndose en un objeto del sistema. El hombre que no puede tomar decisiones, porque no es capaz o porque no se las dejan tomar, ya se encuentra oprimido, debe ser liberado y solo puede haber liberación con los demás, por esto se debe educar con el otro, en diálogo e interacción. Para Freire (1993) los hombres solo se pueden liberar en comunión. Teniendo en cuenta lo anterior, es muy importante la educación partiendo de la realidad del hombre, aunque no toda educación es buena para el hombre, pues Freire denuncia y critica fuertemente la educación bancaria, la cual pretende depositar conocimientos sin ninguna crítica y conciencia "Un acto de depositar en el cual los educandos son depositarios y el educador quien deposita" (Freire, 1970, p. 75) y este tipo de 
educación elimina la curiosidad y el espíritu creativo e inquisitivo en las personas, convirtiéndose el arte de enseñar en una mera trasmisión de conocimientos, con pocas posibilidades de crecimiento y construcción en las personas, como seres humanos creativos, libres, autónomos y capaces de interactuar con el medio que los rodea.

La educación siempre exige la presencia del docente, debe ser una educación liberadora, donde el docente no se sienta dueño exclusivo del conocimiento y no considere que mientras eduque, él es el único que puede depositar conocimientos en sus educandos. La educación con libertad, debe dar apertura de reconocer el otro y reconocer su proceso de aprendizaje e incentivarlo para que siga aprendiendo de forma autónoma y no para domesticarlo de acuerdo al pensamiento de una persona o de una ideología determinada. La educación parte de la historia, una concreta y la otra que construye la persona mientras se educa; se puede decir, que esta historia parte de la realidad misma de la persona. Sin contar con la realidad, la educación nunca podrá ser liberadora, ni transformadora de la misma realidad; de modo que esta, no es más que un espacio de reconocimiento del otro, donde no se parte de la tabla rasa y se entiende que las personas que tienen algún conocimiento, pueden tener otros más. Así mismo, la educación para Paulo Freire, ofrece la posibilidad de ser sujetos, a través de la comunicación y la apertura al otro, siendo un sujeto en constante construcción.

Sólo cuando se conoce a otro, el mundo se hace susceptible de modificaciones, alcanzando varios sentidos diferentes y proponiendo nuevas utopias liberadoras de la misma realidad que se vive en el presente educativo. Hernández (2010) propone partir de un proceso de concientización de sí mismo y del mundo en el que se vive, un mundo que se encuentra en constante creación y dinamicidad y una conciencia que se crea en la articulación de la reflexión y la acción; en este proceso, el sujeto debe ir asimilando y aprendiendo el mundo real, como algo que existe, pero también como algo que puede ser mejor, es decir un mundo mejor y posible.

El pensamiento educativo, liberador, crítico, autónomo y reflexivo de Paulo Freire y de Luis Oscar Londoño Zapata, pretenden que el sujeto se autodetermine y no que se convierta en un objeto. Desde esta idea, el autor comienza a desarrollar su pensamiento educativo popular.

\section{Metodologia.}

Este articulo surge como producto de la investigación hecha sobre la persona de Luis Óscar Londoño Zapata, busca aportar en el ejercicio de memoria transformadora, aportanto en la recuperación de la propuesta de un hombre influenciado por el pensamiento de Paulo Freire y la teología de la liberación y que se ha movido internacionalmente en organismos como la UNESCO, estando vinculado en varias universidades en el país, trabajado en proyectos con comunidades indígenas y campesinas y sobre todo, en la alfabetización y la educación de jóvenes y adultos. 
Para apoyar esta idea se intentara abordar el pensamiento pedagógico de Paulo Freire, especialmente cuando hace referencia a la pedagogía liberadora, dejando el camino abierto para que se hagan reflexiones posteriores sobre la influencia que tuvo la teología de la liberación en Paulo Freire y aquellos aspectos gruesos que Luis Oscar toma del método de Paulo Freire

Se acudió a un análisis documental histórico, retomando para ello, analítica y relacionalmente:

- Documentos oficiales de la iglesia en sus desarrollos sobre la teología de la liberación,

- Se retomaron varios autores que han tomado la palabra popular como una bandera en su pensamiento y una palabra que tiene su asidero fuerte en la teología de la liberación.

- Autores y documentos de la época que han pensado la pedagogía de la liberación, por último,

- Escritores, pensadores Colombianos, sociólogos como Orlando Fals Borda y Luis Oscar Londoño, quienes han trabajado juntos y que además se han destacado fuertemente en el campo de pedagogía en Colombia.

\section{Resultados.}

$\underline{\text { La educación popular en el Contexto latinoamericano. }}$

Durante la década de los 70s, en toda América Latina se originaron movimientos, de carácter popular, entre ellos: movimientos de alfabetización, movimientos políticos, de derechos humanos, entre otros. Muchos de estos, ya habian tenido sus orígenes en la década de los 60 s, y algunos otros se fraguaron en la revolución cubana, como un intento de tomar conciencia de la realidad y establecer una práctica liberadora desde la política. En América Latina, en medio de todos estos movimientos, nació una pedagogía social, que a su vez se convirtió en una educación popular la cual tenía un corte contestatario y político, para la época.

Para Vélez (2011) la educación popular se desarrolla como una práctica de pedagogía, fundada en prácticas sociales que pretenden ser liberadoras y transformadoras, mostrando una pedagogía diferente y que pueda ser propiamente latinoamericana. Esta pedagogía tiene como propósito un proyecto político que busca emancipar en el continente latinoamericano, como una región libre, donde se pueda fundamentar los inicios de una pedagogia liberadora siendo Freire el mayor impulsor.

Según el autor Ezequiel Ander- Egg (1993), en América Latina aparecieron prácticas de educación, trabajo social, promoción cultural, educación de adultos, educación popular y animación sociocultural, que se concretiza en un desarrollo comunitario, Vélez (2011) también dice, que la educación popular es más un discurso de orden político que académico y se ha sistematizado y convergido entre educación, sociedad y política. 
Alfonso Torres profesor de la universidad pedagógica de Colombia, dice (Torres Carrillo, S.f.), que el término "popular" está enfocado en el cambio social de estructuras y en un discurso marxista de los años 60, focalizado en los grupos victimizados por las estructuras de poder capitalista; también afirma, que el movimiento de educación popular ha vivido tres fases: La primera fase se dio con la educación liberadora de Pablo Freire, la segunda con el encuentro de la educación popular con la pedagogía y la tercera se dio con la refundición de la misma, a la luz de los cambios propuestos por la globalización y la internalización del capital.

"La educación popular hereda la pedagogía de Freire. En torno a la discusión y puesta en acción de los planteamientos de Freire y en un contexto signado por la radicalización de las luchas sociales con el imaginario de la revolución surgió en América latina una corriente educativa comprometida con los sueños, proyectos y movimientos de liberación social y cultural: la educación popular. En efecto, la década que comenzaba se caracterizó por auge de movimientos sindicales, campesinos, de pobladores urbanos, de artistas y educadores comprometidos, así como de partidos y movimientos de izquierda política.

En este contexto, la educación popular se fue configurando como una corriente educativa y pedagógica que acompañaba el ascenso de dichas luchas y movimientos de resistencia y liberación" (Vélez, 2011). En la tesis anterior, se muestra cómo surge la educación popular en América latina ligada a las convulsiones políticosociales que estaban ocurriendo en el contexto de la época. Progresivamente la educación popular se ha ido sistematizando en la medida que han surgido modelos de investigación participativa y que ha dado paso a la construcción de un campo intelectual de educadores populares que se ha afianzado en las universidades y centros de estudio.

Teologia de la liberación y educación popular.

En el proceso de consolidación de la educación popular, no se puede olvidar la teología de la liberación y el aporte que le ha hecho está a la misma. Desde su método, la teología de la liberación ha traspasado su método teológico a la educación popular, que de un quehacer teológico, se ha transformado en un quehacer pedagógico. La educación popular, de la cual se oyeron sus gritos por toda América Latina, en Colombia fue silenciada por los gobiernos de Alfonso López Michélsen (19741978) y Julio cesar Turbay Ayala (1978-1982); lo mismo sucedió en otros países latinoamericanos en un intento por ascender los grupos de izquierda al poder, y la educación popular, se encontraba identificada como un movimiento izquierdista.

La educación popular a lo largo de estos años ha querido aportar una acción y reflexión sobre el sujeto marginado y los centros de poder, ha buscado crear una conciencia liberadora y una acción educativa transformadora. El congreso de los educadores populares, señala que "Los educadores populares en la práctica educativa que hacemos con las comunidades debemos aprender a escuchar y aprender a aprehender. Hay que enseñar a pensar y darle la oportunidad a la 
gente de hacer rupturas con la cultura que domina, hay que educar para la crítica" (Vélez, 2011, p. 141).

En la actualidad, la educación popular se ha vinculado en la educación formal, intentando promover competencias que incentiven la inclusión y el diálogo intercultural. "Intentan formar ciudadanos responsables y conscientes de la acción social y haciendo una critica a las desigualdades propuestas por el capitalismo salvaje. Intentan recuperar las identidades nacionales y los patrimonios culturales ambientales, presionando a los Estados para que en sus constituciones incluyan el respeto por la diversidad y la riqueza ambiental de los países" (Vélez, 2011, p. 143).

Retomando la idea original de Paulo Freire, quien era un hombre católico y creyente, no se puede deslindar esta idea de su pensamiento pedagógico. Hay que reconocer que esta realidad de fe en la vida de Paulo Freire, le permitía acercarse sin escrúpulos a la teología de la liberación, de la cual, toma su método para construir lo que podemos llamar también, una pedagogía de la liberación. Evidentemente Paulo, vive una época de profundos cambios y transformaciones que van a afectar profundamente su pensamiento y la forma de concebir entender y enfrentarse a la vida, lo que también lo hace crear un pensamiento pedagógico propio, que podemos denominar "pedagogía liberadora".

Freire, trabajó como profesor de portugués en el colegio "Oswaldo Cruz", donde fue adquiriendo su experiencia como educador, a pesar de que había estudiado leyes en la universidad Federal de Pernambuco. Es así, como en el año de 1963 alfabetiza 300 trabajadores rurales y lo hace en 45 dias, teniendo tanto éxito que fue invitado por el presidente de Brasil Joao Goulart a reorganizar el proceso de alfabetización nacional en el país en el año 1964, y estaba proyectado crear 20.000 círculos de cultura que llegará a dos millones de analfabetas, pero el trabajo se ve interrumpido por el golpe militar del 31 de marzo de 1964 protagonizado por el general Humberto Alencar Castelo Blanco y después de permanecer 75 días en la cárcel, se refugió en la embajada de Bolivia y luego pasó a chile donde permaneció algún tiempo (Paulo Freire, sf).

Es bueno resaltar que mientras esto sucedia, también se desarrollaba el concilio vaticano II, que sería una de las fuentes inspiradoras de la teología de la liberación. Los hombres que originaron la teología de la liberación en América Latina, tenían un pensamiento humanista similar al de Paulo Freire, y compartian muchas cosas en común. En primer lugar, todos eran latinoamericanos, en segundo lugar, conocieron experiencias de extrema pobreza, injusticia y marginación, en tercer lugar, eran hombres creyentes y católicos, además, tenían una alta formación intelectual, pues muchos de ellos fueron formados en las universidades europeas.

Paulo Freire, dijo con sus propias palabras, qué él era un creyente en Jesucristo y este ha sido uno de los fundamentos de la teología de la liberación. Los teólogos de la liberación se centran en la encarnación del hijo de Dios y en su humanidad. Presentan a Jesucristo como un hombre liberador de las injusticias y las opresiones, un Jesucristo que se hace carne y real, que acompaña al pueblo cristiano en su 
sufrimiento y que no se queda solo en los manuales de teología. (Pedagogía de la liberación, sf).

Paulo Freire en el año de 1962, intenta implementar un nuevo método, para alfabetizar, pero también quiso sembrar la conciencia critica en las personas. Toda América Latina en la década de los 60s se permea de un lenguaje liberacionista, ideas que se fueron concretando en lo que conocemos como la teología de la liberación y la pedagogía de la liberación de Paulo Freire.

A la teología de la liberación se le ha acusado de marxista y de tener ideas totalizantes, opuestas a la fe cristiana. En algunos sectores conservadores de la iglesia, la endilgan de hacer una interpretación política de la fe, lo que la hace, parcial y errática y por lo tanto, convirtiéndose en un riesgo para el orden jerárquico católico. Esta teología tuvo sus origenes en hombres como pedro Casaldáliga, Gustavo Gutiérrez, Leonardo Boff, Clodovis Boff, John Sobrino, Enrique Dusel. A esto hay que añadir que se realizaron talleres populares de teología con la gente, lo que hizo que surgiera una reflexión crítica y actualizante de la realidad. (Girardi,Forcano y Vigil, 1987, p. 438)

Empezó a generarse una investigación participativa del colectivo popular; se realizaron evaluaciones de la realidad, y se intentó iluminar a la luz de la Sagrada Escritura, la propia historia y la vida cotidiana. La gente comenzó a ser educada desde el punto de vista de los oprimidos y se consideró al pueblo como un objeto de acción y decisión.

Se fueron creando y desarrollando organizaciones populares, expresadas en comunidades cristi-escuelas e iglesias y con la idea de formar al pueblo como un sujeto cultural, un sujeto político y un sujeto económico, es decir, un conjunto de personas capaces de ser autónomos y creativos, como la reunión de los teólogos de la liberación y del tercer mundo que dio cuerpo a lo que conocemos como teología de la liberación. (a) El encuentro del Escorial del 8 al 15 de julio de 1972, que se caracterizó porque algunos teólogos latinoamericanos se reunieron con algunos europeos y abordaron el tema del método y el pensamiento teológico. (b) el encuentro efectuado en México en 1975 del 11 al 15 de agosto, que se centró en el método teológico más apropiado para las necesidades de la iglesia latinoamericana. (c) El encuentro que se realizó en Ditroit del 18 al 24 de agosto de 1975, este encuentro realizado en estados Unidos fue muy importante, pues se reflexionó sobre los compromisos con los hermanos cristianos de América latina que lucha por la liberación. (d) El encuentro de Dar es Salaam que se realizó del 5 a al 12 de agosto de 1976 y se reunieron los mejores teólogos de Asia, África y América Latina, para reflexionar sobre las situaciones de opresión y colonialismo y tuvo por nombre "teólogos del tercer mundo". (e) El encuentro para preparar la conferencia del episcopado latinoamericano en Puebla de los Ángeles que se realizó a finales de 1976 y que se esforzó por recoger el trabajo teológico de Medellín como uno de los puntales de la teología de la liberación. 
El objetivo de todo esto, es el protagonismo cultural del pueblo ante la amenaza de la cultura dominante, liberal y demócrata que trata de imponer sobre los demás a nivel mundial un pensamiento único y totalizador, por esta razón, la teología de la liberación lucha por reconocer el derecho de la autodeterminación en sindicatos y asociaciones.

La teología de la liberación se centra en tres palabras claves "Teologia" "Pueblo" "Sujeto", esta se pregunta si el pueblo es el sujeto de la liberación porque un pueblo que no es sujeto, es una masa amorfa, sin forma que puede ser manipulado culturalmente y religiosamente. El pueblo como sujeto, debe tomar conciencia de su opresión y afirmarse como sujeto histórico, entendiendo como "pueblo" el conjunto de sectores populares que se encuentran en lucha.

Desde este punto de vista, la teología, nace desde la misma opresión del ser humano y tanto el pueblo como el teólogo realizan un quehacer teológico. El teólogo no es el propio pueblo, pero es un especialista que orienta al pueblo y hace teología con el pueblo.

El teólogo de la liberación camina con el pueblo a la luz de la fe y de la Sagrada Escritura, para que el pueblo pueda expresarse libre y creadoramente en la sociedad. Esto hace necesario, sobre todo, que el teólogo sea un verdadero pedagogo, que propenda y haga real una educación popular liberadora, una educación con metodología y afianzada en la investigación popular. Cuando se dice popular se hace referencia a que el "pueblo" es el sujeto, para lo cual, van a afirmar algunos teólogos que se definía la educación como "popular" para significar que el propio pueblo estaba llamado a educar al pueblo".

En este orden, los teólogos de la liberación empezaron a reunirse con periodicidad, cada trienio, como por ejemplo: Sao Pablo, Brasil (1980); la india (1983); México 1986 y a lo largo de toda América y de la década de los 60s en adelante, se fueron desarrollando y creando talleres populares de teologia, que han sido el producto de una evangelización inculturada y apoyada en la lectura de la Palabra de Dios.

Desde aquí, se puede ver que el sujeto y el método en teología, tienen una relación muy estrecha, y mientras esto permanezca, es un signo claro que la comunidad misma se convierte en un sujeto, pues la Palabra de Dios le habla a cada individuo en particular, pero también le habla a un colectivo comunitario que tiene el nombre de pueblo. Desde aquí, se hace preciso el método de la teología de la liberación: "Ver" "Juzgar" y "Actuar". Es un método que se desarrolla en la historia y que ha tenido sus bases en el Concilio Vaticano II, que invita a todos los católicos a abrirse al mundo y reconocer la Iglesia como sacramento de salvación. La Conferencia del Episcopado Latinoamericano en Medellin, dijo que en América Latina se encontraban millones de personas en inhumana pobreza y esta situación, no podía ser voluntad de Dios. Por lo tanto, se empieza a realizar una nueva reflexión, tomando conciencia del ser y quehacer como iglesia.

"Un sordo clamor brota de millones de hombres, pidiendo a sus pastores una liberación que no llega de ninguna parte", "la experiencia secular de dolor de los campesinos, de los indigenas y los negros, que toman nuevas formas en las 
barriadas y en los campos latinoamericanos y cuyo clamor si en momentos pareció sordo. Se fue haciendo cada vez más claro y fuerte" (Episcopado Latinoamericano, 1979). En América Latina hay mortalidad infantil, falta de vivienda, problema de salud, salarios de hambre, desempleo y subempleo, desnutrición, inestabilidad laboral, migraciones masivas, desapariciones forzadas y muchas formas de injusticia generalizada, estructurada e institucionalizada (Experiencia de lectura del Evangelio con los pobres en Solentiname de Ernesto Cardenal).

Todas estas son situaciones de pecado estructural y en todos los que sufren debemos reconocer el rostro de Cristo sufriente (Episcopado Latinoamericano, 1979). Hoy tenemos la sangre de Dios en el pobre que sufre y el color de la sangre de Cristo, en el amor, y esto es lo que recoge la teología de la liberación. Esta invita a convertirse y configurarse con Cristo, siendo hermano del pobre que sufre. En la sociedad actual hay muchas personas que se parecen al joven rico del evangelio, que se encontraba bien formado y era un cumplidor de los mandamientos, y preguntó a Jesús ¿qué tenía que hacer para ganar la vida eterna? y recibió una respuesta clara y amorosa del maestro, "comparte los bienes con los pobres y entonces sígueme" (Mt 1,15). La conferencia de Puebla nos va a decir que no todas las personas en América Latina se han comprometido suficientemente con los pobres e incluyendo personas que viven inmersas en el saber teológico.

Muchos han comprendido la teología como un saber racional y se han quedado en una teología escolar y muchas veces esta clase de teología se ha convertido en una ideología al servicio de los poderes económicos, políticos, de un sistema capitalista liberal, que excluye grandes masas de población, en la mayoría de países. La teología de la liberación es contraria a este pensamiento y se afianza en el mismo hombre, al respecto Karl Rahner nos va a decir "toda verdadera teología es antropología; y toda verdadera antropología es teologia".

La historia de la salvación, es la historia de la encarnación del hijo del hombre. La teología entonces debe hacer crítica y reflexionar sobre el mismo hombre y un hombre integral que no se encuentre desarticulado. La reflexión teológica debe partir desde un hombre holístico, que debe ser liberado de los sistemas opresores y sobre todo que debe ser liberado del pecado. Cristo nació, vivió y murió para la liberación de los pobres y la construcción de un reino de amor 1 (Jn 4,7-8). De modo, que sólo un creyente en Jesucristo puede hacer teología de la liberación. "Los pobres me enseñaron a vivir y a comprender el evangelio", ha sido la declaración de varios teólogos de la liberación. Todo este pensamiento teológico se refleja en un libro que marcó un hito en la teología de la liberación. Gustavo Gutiérrez "la teología de la liberación". Este libro dibujo trazos para elaborar una teología de la liberación más sistemática y poder reflexionar sobre el quehacer teológico.

Muchos acontecimientos en América Latina se pueden entender en las causas que generaron este quehacer teológico, que se afinca en una opción fundamental por los pobres y en una crítica a la misma realidad. La teología de la liberación fue configurando un método enraizado en "un saber y un quehacer teológico" por lo tanto, los teólogos de la liberación y los teólogos del tercer mundo realizaron muchos 
encuentros para lograr este objetivo. Se dieron encuentros como el de Escorial en julio de 1972, en México en 1975, también en Detroit en el mismo año, la conferencia de puebla, distintas reuniones donde los teólogos de la liberación reconocieron el aporte de la teología Europea en este nuevo quehacer teológico y a la vez, hicieron una reflexión y crítica de la realidad y también analizaron la importancia de la conferencia de Medellín y la reflexión teológica que surgió desde allí.

Entre los teólogos de la liberación más importantes podemos mencionar a Segundo Galilea, J.L segundo, H Assmann, Miguez Bonino, Gustavo Gutiérrez, Leonardo Y Clodovis Boff, Raul Vidales, Ronalod muñoz, Jhon sobrino, Pablo Richard, Enrique Dusel, Ignacio Ellacuria entre otros principales exponentes de la Teología de la Liberación.

Esta teología entonces nos muestra como la evangelización tiene una clara dimensión concientizadora de la realidad y sensibilizadora, de modo que una espiritualidad que no libere al hombre integral no puede ser autentica. Y por lo mismo el Papa Juan Pablo Segundo llego a afirmar que "la teología de la liberación es conveniente y necesaria" porque debe suscitar una fuerte solidaridad entre los cristianos y no solamente en el tercer mundo, sino en todos los continentes.

Muchos teólogos europeos se solidarizaron con la teología de la liberación como: Congar, Chenú, González Faus, Metz, Karl Rahaner. Schilebeekx y muchos centros y universidades europeas han condecorado a los teólogos de la liberación y hasta los gobiernos, como el de España, con el galardón "Príncipe de Asturias".

Dentro de este contexto, debemos entender a Paulo Friere, pero enfocándonos sobre todo en su pedagogía de la liberación. La teología de la liberación se movia sobre todo en la crítica y la reflexión, para iluminar la praxis teológica del actuar humano en los grupos eclesiales; el mismo camino ha tomado Freire con su pedagogía crítica y reflexiva, sobre la realidad. Paulo Freire, ha elaborado una teoría de la educación recorriendo niveles teológicos, antropológicos y metodológicos como consta en los documentos de la Conferencia del Episcopado latinoamericano en Medellín Números 1,2,7,16.

En la teología no puede haber teología de la liberación sino hay pedagogía de la liberación, los hombres deben ser liberados de la opresión y esto implica una educación para que sean más humanos y para que sea un verdadero sujeto cultural e histórico. Freire, estuvo influenciado por las corrientes filosóficas de la fenomenología, el existencialismo, el personalismo, el marxismo y el hegelianismo. Al estar relacionado con el consejo mundial de las iglesias, viajó por las tierras de África, Asia, Oceanía y América, lo que hace suponer que tuvo un acercamiento con la teología protestante sin dar a entender que nunca renunció a su fe católica, pues a su padre le manifestó que quería ser católico.

Freire y la educación popular.

Paulo Freire debió retomar conceptos de la teología de la liberación y aplicarlos a su quehacer pedagógico. La teología de la liberación y la pedagogía de la liberación 
de paulo Freire comparten términos como los siguientes: Liberación, oprimido, Pedagogía crítica, reflexión, método, popular, sujeto, objeto, quehacer pedagógico, quehacer teológico, formación, entre otros. Pero de todos estos términos, es muy importante centrarnos en la palabra popular. En la teología de la liberación, diriamos que el pueblo, cuando reflexiona sobre sí mismo y hace una crítica constructiva se evangeliza a sí mismo. Lo mismo se podría decir en la educación popular. Cuando el pueblo reflexiona y hace una crítica constructiva en su propio interior, se puede decir que se educa así mismo "uno de los esfuerzos más relevantes es el de la educación de los grupos populares que son potencialmente capaces de actuar como agentes conscientes de un cambio social" (Girox, 1990). La educación popular debe entenderse como un aporte a las luchas y organizaciones populares que llevamos adelante y que nos enseñan.

Según Freire (1970), popular debe entenderse como un sujeto, que a la vez es un colectivo que se forma y se educa y es sujeto que se relaciona e interactúa con el mundo. Cuando Paulo Freire fue profesor de Harvard por un año, publicó el libro "Pedagogía del oprimido" donde demuestra que la educación debe ser un proceso mediante el cual todas las personas implicadas en él, se educan y son educadas a la vez, y esta es la mejor definición que se puede extractar de Paulo Freire sobre educación popular. Popular hace referencia a un sujeto, colectivo, que a la vez es una agrupación de grupos populares que se educan y a la vez son educados.

La teología de la liberación planteó la esperanza y los sueños, Paulo Freire plantea una educación popular, participativa y una movilización cultural que lleve a todos los sectores marginados a que tengan un sentido crítico de la vida y una participación política y cultural. Él no es solo un hombre de la razón, es un hombre del afecto y de la preocupación por el otro. No se puede conocer con rigor cuando se desprecian los sentimientos, las intuiciones, los sueños, los deseos, porque el cuerpo entero conoce de este modo, afirma Paulo Freire (1969). Para él es importante el diálogo donde nadie educa a nadie, pues todos nos educamos entre sí, mediatizados por un mundo propio y donde siempre tendremos la posibilidad de producir acuerdos, argumentos y de entablar negociaciones, formular propuestas y solucionar conflictos. La educación popular tiene que ver entonces con la educación para la autonomía, para que el hombre y los pueblos puedan ser libres y autodeterminarse libremente, construyendo su propia identidad politica y cultural.

No se sabe qué fue primero, si la teología de la liberación o la pedagogía de la liberación, lo que sí se puede decir, es que ambas se complementan, pues sin una verdadera pedagogía de la liberación no puede haber teología de la liberación. Tanto la pedagogía de la liberación como la teología de la liberación, teleológicamente apuntan hacia la autonomía en las personas, una crítica reflexiva, una concientización de la realidad, una formación popular, pero sobre todo, una liberación de la persona integral de cualquier forma de opresión, que quiere impedir que las personas sean sujetos que se relacionan con el mundo en libertad.

El pueblo no puede ser una masa amorfa que es manipulada por las estructuras y sistemas de poder, pues tanto Paulo Freire con su pedagogía de la liberación, como 
la teología de la liberación en sus diferentes representantes, ha luchado y siguen luchando para que el pueblo sea un sujeto político y cultural que se relaciona con el mundo y que tiene la capacidad y la libertad de autodeterminarse y buscar su propia identidad. A esto se le llama Educación popular y teología popular o de la liberación.

Luis Oscar Londoño Zapata.

Luis Oscar Londoño Zapata, educador popular colombiano, Sociólogo, investigador popular, nacido en Medellín (Antioquia), Colombia, el 28 de mayo de 1934, impulsor de la educación popular y de adultos en Colombia, una vida al servicio de la lucha popular, su labor reconocida con la Medalla "Simón Bolivar". Del ministerio de Educación de Colombia, Medalla Cívica "Camilo Torres", Estrella de Plata. Universidad Católica de Oriente y el reconocimiento Paulo Freire, Mención a "Toda una Vida a la Alfabetización". Universidad Nacional Abierta y a Distancia -UNAD- Bogotá. 2009

Luis Oscar Londoño, nutrió su propuesta educativa y pedagógica desde los aportes de Paulo Freire. Conceptos como educación popular, teología de la liberación, concientización, crítica, reflexión y autonomía están presentes en el pensamiento pedagógico de Luis Oscar Londoño zapata. Estas influencias lo llevaron a concebir la escuela como proyecto cultural; postura bajo la cual se percibe la escuela como generadora de hombres preocupados por su comunidad, dispuestos a contribuir con su aporte reflexivo y solidario, a transformar las realidades de su entorno.

En esta concepción, para Luis Oscar Londoño Zapata el maestro en la escuela debe asumir roles acordes a este propósito, donde el maestro debe vincular lo académico, lo cultural, la formación de valores con métodos abiertos de enseñanza.

Luis Oscar toma el método de Paulo Freire quien, prácticamente creó una escuela pedagógica latinoamericana, que propende por la educación del hombre para que sea autónomo, reflexivo, crítico y capaz de enfrentar su medio para transformarlo y elevarlo a mejores condiciones y esto en relación con los demás; de modo que en Paulo Freire, existe una pedagogía social y critica.

Todos estos pensamientos, la teología de la liberación y la pedagogía de la liberación, han confluido en una palabra que se puede denominar popular, adquiriendo el nombre de pedagogía popular, entendiendo popular, en cuanto se habla de autonomía, reflexión, crítica y aprendizaje de contexto.

Desde la concepción de Luis Oscar se considera al maestro como un investigador, que genere discusión y pensamiento crítico y reflexivo durante la clase, también debe ser un sujeto personalizante, que es capaz de diagnosticar la situación de sus estudiantes, detectando los vacíos y descubriendo potencialidades; es alguien que respeta el ritmo de aprendizaje de los estudiantes, estimulando a los rápidos para que aborden material adicional e interesándose por los más lentos para que encuentren los obstáculos y potenciar mejor su aprendizaje, un maestro personalizador que motive a los estudiantes con nuevas técnicas y métodos. 
El maestro debe ser un educador que promueva cultura en la comunidad, en costumbres, música, folclor, literatura local y regional, cultura escrita y oral, el arte en sus diferentes manifestaciones, de la recreación, del trabajo, de la vida social y comunitaria en sus diferentes manifestaciones.

Este tipo de maestros deben crear y generar escuelas que asuman un papel protagónico en el rescate de la identidad cultural de un pueblo, entendiendo que la cultura es el modo más eficaz de comunicación y participación de un pueblo.

La escuela como proyecto cultural debe permitir el afianzamiento del saber popular, la discusión de los problemas de la comunidad y el empoderamiento de su autonomía, para que la comunidad se convierta en un motor de desarrollo.

La escuela no solamente enseña un oficio, sino que desarrolla al individuo integralmente. La escuela enseña y vive los valores, como instruye en el saber universal, en los aspectos sociopolíticos, económicos, científicos y técnicos del entorno cercano y de la cultura universal.

Esto implica necesariamente que el maestro profundice en sus conocimientos, que se capacite en los avances de la ciencia y la tecnología y que se acerque con rigor a los saberes humanísticos del hombre. La escuela como proyecto cultural debe promover la democracia y a la vez ser un centro dinamizador de las potencialidades de sus estudiantes abriendo posibilidades de transformación en el barrio, en la comuna, en la vereda y en la ciudad. La escuela puede permitir la construcción de un ideal pedagógico a partir de los intereses de la misma comunidad, una pedagogía que sea inclusiva y que apunte a la integralidad de la persona.

\section{Conclusiones.}

Se puede concluir diciendo que, Paulo Freire buscó crear un pensamiento pedagógico diferente, que comúnmente se ha conocido como pedagogía liberadora: este pensamiento ha sentado las bases para crear una escuela de pensamiento pedagógico propio de Latinoamérica y muchos pedagogos latinoamericanos han construido y siguen construyendo sobre las bases de Freire, como es el caso del brasileño Carlos Brandau, el colombiano Orlando Fals Borda y el ecuatoriano Gonzalo Orbe, también el maestro Luis Oscar Londoño Zapata que apoyado en las ideas de Freire, reflexionó sobre la educación liberadora y popular, pero también pensó la escuela como un proyecto cultural-humanitario.

En Colombia se vislumbra una nueva escuela, que se encuentre fundamentada y apoyada en una concepción filosófica que no sea represora y tradicional; sino que promueva un maestro que recupera su propia idoneidad, sus cualidades morales y éticas, su afán por ser un mejor maestro, de ser alguien innovador que sepa construir pensamiento y creatividad con los demás, que esté más capacitado, que sea más justo, en pocas palabras, que sea más humano y que tenga su propia identidad, pues la escuela ante todo es un proyecto cultural-humanitario, que debe girar en torno a una pedagogía liberadora, pues las pedagogias que enrutan los 
sistemas educativos de la mayoría de países, nos preparan para el mundo de la producción y el consumo, no para que seamos más humanos y una pedagogía de estas, ya nos hace esclavos.

Luis Óscar Londoño Zapata, le ha dado mucha importancia a la palabra popular y ha reflexionado profundamente, sobre la educación popular, pensamiento que ha construido con la influencia de la teología de la liberación, la pedagogía de la liberación y Paulo Freire.

Este pensamiento de su pedagogía popular, se refleja en el texto- la escuela como proyecto cultural- en donde se propone "reivindicar el papel protagónico de la escuela como articuladora de las gestiones comunitarias, catalizadora del saber popular, estimuladora de la participación de la comunidad Gen la elaboración de proyectos colectivos de vida, potenciadora de la creatividad, y de las esperanzas de la comunidad" (Ministerio de Educación Colombia, 1988).

Una lectura crítica al saber pedagógico, debe permitir un acercamiento a la educación desde un punto de vista liberador; se podría decir que una educación que no sea liberadora, no debe ser tenida en cuenta, pues no permite que el ser humano sea autónomo, reflexivo, crítico y se encuentre a merced de sistemas de opresión. 


\section{Referencias Bibliográficas.}

Freire, P. (1970). Pedagogía el oprimido. Mexico: Siglo XXI.

Freire , P. (1993). Pedagogía de la esperanza: un reencuentro con la pedagogía del oprimido. Mexico: Siglo XXI.

Freire, P. (1969). La educación como práctica de la libertad. Mexico: Siglo XXI.

Girardo, G., Forcano, B., \& Vigil, M. (1987). Trichera teológica. Para una teología de la liberación desde Nicaragua. Nicaragua: Loguez Ediciones.

Girox, H. (1990). Los profesores como intelectuales. Barcelona: Paidós.

Hernandez, O. (2010). Hacia una antropología de la educacion desde la obra de Pablo Freire. Magistro, 4(8), 19-32.

Londoño Zapata, L. O. (1983). Alfabetizacion Rural. Bogotá: Copiyepes.

Londoño Zapata, L. O. (1991). El analfabetismo funcional, Un nuevo punto de partida. Bogotá: Magisterio.

Londoño Zapata, L. O. (1995). Hacía una nueva institucionalidad en Educación de jóvenes y adultos. Bogotá: Convenio Andres Bello.

Londoño Zapata, L. O. (1996). Plan decenal de educación. Conversaciones Pedagógicas.

Londoño Zapata, L. O. (2008). Educación en el medio rural y enfoques del desarrollo. Aproximaciones al estado del arte. Medellin: Universidad de Antioquia.

Londoño Zapata, L. O. (2008). Jurisdicción Especialy Justicias indigenas en Risaralda, Chocó y Urabá antioqueño. Medellin: Gráficas Ibañez.

Ministerio de Educación Colombia. (1988). La escuela como proyecto cultural. Bogotá: Ministerio de Educación. Colombia.

Salanova Sánchez, E. (2000). Pablo Freire. Obtenido de uhu.es: http:/ / www.uhu.es / cine.educacion/figuraspedagogia/0_paulo_freire.htm

Torres Carrillo, A. (S.f.). La educacion popula. Evolucion reciente y desafios. Recuperado el 15 de Mayo de 2014, de Universidad Pedagógica Nacional: http:/ / www.pedagogica.edu.co/storage/ps/articulos/pedysab04_05arti.pdf

Vélez, C. (2011). La educación social y popular en Colombia. Relaciones y búsquedas: treinta años de legitimidad. Guillermo de Ockam(1), 135-143.

Zapata Londoño, L. O. (1997). La alfabetización atrapada de nuevo. Educación de Adultos y desarrollo, 127-134. 